\title{
FILOSOFIA COMO POLÍTICA CULTURAL: REDESCRIÇÕES, IDENTIDADE E COMUNIDADES INCLUSIVAS
}

\author{
PHILOSOPHY AS CULTURAL POLICY: REDESCRIPTIONS, IDENTITY AND INCLUSIVE \\ COMMUNITIES
}

Paulo Andrade Vitória*

\section{RESUMO}

No presente artigo defendo a tese rortyana de que as relações de poder serão mais justas se começarmos a nos redescrevermos linguisticamente de maneira nova, criando um padrão de conduta linguístico que, se adotado, promova formas apropriadas de comportamento não linguístico. Para tanto, abordo a concepção de jogos de linguagem do segundo Wittgenstein, que nos permite extrair a tese de que a linguagem é contingente. Defender o caráter contingente da linguagem é simplesmente defender o caráter natural, social e histórico da linguagem. Apresento a ideia de McDowell de que a entrada em um jogo de linguagem significa a entrada no espaço das razões. Como Rorty, acredito que a identidade humana pode ser redescrita se adotarmos novas formas de descrevermos a nós mesmos e às nossas instituições políticas. A sugestão do presente artigo é de que devemos adotar vocabulários ou jogos de linguagem que incluam termos e discursos capazes de promover a tolerância e o diálogo e excluam discursos de ódio e preconceito, o que pode levar à construção de sociedades mais inclusivas.

PALAVRAS-CHAVES: Cultura. Jogos de linguagem. Contingência. Identidade.

Comunidades inclusivas.

\begin{abstract}
In the present article I defend the rortyana thesis that power relations will be more fair, if we begin to linguistically redesign ourselves in a new way, creating a pattern of linguistic conduct that, if adopted, promotes appropriate forms of non-linguistic behavior. Therefore, I approach Wittgenstein's conception of language games, which allows us to extract the thesis that language is contingent. Advocate the contingent character of language is simply to defend the natural, social, and historical character of language. I introduce McDowell's idea that get into a language game means entry into the space of reasons. Like Rorty, I believe that human identity can be redrawn if we adopt new ways of describing ourselves and our political institutions. The suggestion in this article is that we should adopt vocabulary or language games that include terms and discourses capable of promoting tolerance and dialogue and exclude discourses of hatred and prejudice, which may lead to the construction of more inclusive societies.
\end{abstract}

KEYWORDS: Culture. Language games. Contingency. Identity. Inclusive communities.

\footnotetext{
${ }^{*}$ Bacharel e Licenciado em Filosofia pela FAJE - Faculdade Jesuíta de Filosofia e Teologia. Mestre pela UFMG. Doutorando em filosofia pela UFMG. Professor de Filosofia da PUC Minas e do ISTA - Instituto São Tomás de Aquino. E-mail: pauloandradebh@gmail.com.
} 


\section{INTRODUÇÃO}

Antes de abordar o tema do presente artigo, gostaríamos de fazer algumas considerações: (i) no meio acadêmico filosófico, em geral, se distinguem dois modos de se fazer filosofia. Por um lado, o modo continental, por outro, o modo analítico; (ii) consideramo-nos herdeiros do modo analítico de fazer filosofia, pelo interesse pela análise dos argumentos, pela clareza dos enunciados e pelos problemas filosóficos, traços característicos da filosofia analítica; (iii) neste modo de fazer filosofia, a linguagem ocupa lugar de destaque. Os filósofos analíticos estão quase sempre dispostos a falar da linguagem. A pergunta que os filósofos analíticos estão inclinados a fazer não é do tipo "o que é a justiça?”, mas “o que queremos dizer com os predicados justo e injusto?”. Já as investigações sobre o conhecimento, na filosofia analítica, tomam a forma de uma reflexão sobre os enunciados da forma "X acredita (ou sabe) que P".

Por se preocuparem eminentemente com a análise da linguagem, os filósofos analíticos são acusados frequentemente de não se interessarem mais pelas coisas, pelo mundo que nos rodeia, mas apenas por palavras. São retirados do domínio filosófico e colocados no da linguística. Contudo, acredito que, ao falarmos da linguagem, acabamos falando do resto das coisas. Os outros filósofos também falam da linguagem, e não somente falam, mas estão imersos nela, embora não se deem conta disso. Wittgenstein $(1975, \S 109)$ ilustra esse ponto quando diz: "a filosofia é uma luta contra o enfeitiçamento do nosso entendimento pelos meios da nossa linguagem". De qualquer forma, considero a divisão radical, entre analíticos e continentais, contraprodutiva ao debate filosófico.

É com esses esclarecimentos que nos debruçamos sobre a questão da política cultural. Os filósofos contemporâneos que embasam esta reflexão sobre o tema talvez não sejam os que tradicionalmente se destaquem em tais assuntos. ${ }^{1}$ Talvez alguns não sejam nem mesmo conhecidos do público filosófico. São eles: Richard Rorty, Donald Davidson, Wilfrid Sellars, Robert Brandom, John McDowell e Wittgenstein. Estes me permitiram entender: (i) o caráter contingente da linguagem e (ii) a possibilidade da construção de novas identidades no âmbito cultural e político por meio de redescrições linguísticas.

\footnotetext{
${ }^{1}$ Para citar alguns: Michel Foucault (1926-1984) e Hannah Arendt (1906-1975).
} 
Ao falar de questões culturais e políticas tocamos na questão do poder. Vamos adotar a ideia relacional de poder como entendida por Hannah Arendt; tal ideia supõe a existência de duas visões políticas distintas. Disso podemos inferir que relações de poder estão presentes em instituições, entre homens e mulheres, entre grupos étnicos, entre jovens e idosos, etc. A reflexão sobre a contingência da linguagem, enquanto capaz de formar a identidade dos indivíduos, nos ajuda de alguma maneira, também, a refletir sobre a questão da violência, já que "a forma mais básica de manifestação do poder é a violência" (ARENDT, 2001, p. 31). Nesse sentido, construir relações de poder mais justas implica a redução da violência.

No presente artigo será adotada e defendida a tese rortyana de que as relações de poder serão mais justas quando começarmos a nos redescrever linguisticamente de maneira nova, criando um padrão de conduta linguístico que, se adotado, promova formas apropriadas de comportamento não linguístico. Por exemplo, podemos pensar na redescrições de instituições com novas roupagens, capazes de incentivar políticas inclusivas e de tolerância. Por tolerância aqui entendemos o respeito pelas ideias, crenças ou práticas que sejam diferentes ou contrárias às nossas.

Nossa estratégia argumentativa será a seguinte: (i) explicitar a concepção de linguagem adotada por Rorty, destacando o seu caráter contingente; (ii) apresentar a ideia de racionalidade defendida por McDowell e (iii) defender que a linguagem, compreendida em termos de vocabulários completos ou jogos de linguagem, é capaz de moldar o comportamento linguístico e não linguístico dos indivíduos.

\section{O CARÁTER CONTINGENTE DA LINGUAGEM}

Vejamos o que diz Wittgenstein nas Investigações filosóficas:

\footnotetext{
Quantas espécies de frases existem? Afirmação, pergunta e comando, talvez? - Há inúmeras de tais espécies: inúmeras espécies diferentes de emprego daquilo que chamamos de "signo", "palavras", "frases". E essa pluralidade não é nada fixo, um dado para sempre; mas novos tipos de linguagem, novos jogos de linguagem, como poderíamos dizer, nascem e outros envelhecem e são esquecidos.... O termo "jogo de linguagem" deve aqui salientar que o falar da linguagem é uma parte de uma atividade ou de uma forma de vida. (WITTGENSTEIN, 1975, §23).

$[\ldots]$

Comandar, perguntar, contar, tagarelar pertencem à história natural de nossa natureza assim como andar, comer, beber, jogar. (\$25).

$[\ldots]$
}

Sapere aude - Belo Horizonte, v. 9 - n. 17, p. 140-152, Jan./Jun. 2018 - ISSN: 2177-6342 
Seguir uma regra, fazer uma comunicação, dar uma ordem... são hábitos (costumes, instituições). (\$199).

Gostaríamos de extrair da concepção de linguagem do segundo Wittgenstein algumas teses que consideramos importantes para o ponto que vamos defender. Uma dessas teses é a de que a linguagem é contingente. Defender o caráter contingente da linguagem é simplesmente defender o caráter natural, social e histórico da linguagem. É defender que as línguas, como manifestação da linguagem, são construídas socialmente. ${ }^{2}$ Tese que também é defendida por Rorty (2007, p. 28): “as línguas humanas são criações dos próprios seres humanos". Entender a linguagem nesses termos implica: (i) não enxergar a linguagem como algo divino ou sobrenatural e (ii) não vê-la como conferida aos humanos para representar o mundo de forma acurada, como um espelho reflete uma imagem.

Reconhecer o caráter contingente da linguagem é ter consciência de que as afirmações verdadeiras ou corretas que fazemos do mundo não são dadas pelo mundo. É entender o termo verdadeiro como propriedade de entidades linguísticas e não como propriedades do mundo. $\mathrm{O}$ mundo é indiferente às nossas descrições. O mundo existe, já as descrições dele não. Como diz Rorty (2007, p. 30): “o mundo não fala. Só nós o fazemos”. O mundo, depois de nos programarmos com uma linguagem, pode fazer-nos sustentar convicções, mas não pode propor uma linguagem para falarmos. Somente outros seres humanos são capazes de fazê-lo (RORTY, 2007, p. 30). Isso pode ser formulado em argumento como segue:

(P1) Se a linguagem é contingente, então nossas descrições do mundo são modos de nos ajustarmos a ele.

(P2) A linguagem é contingente.

(C) Logo, as nossas descrições do mundo são modos de nos ajustarmos a ele.

As descrições que os seres humanos fornecem do mundo podem ser entendidas, em termos wittgensteinianos, de jogos de linguagem. ${ }^{3}$ A ideia de jogo de linguagem, enquanto forma de vida, é importante, quando nos permite compreender as frases como parte de vocabulários inteiros. O que chamamos aqui de vocabulários inteiros são certas descrições do

\footnotetext{
${ }^{2}$ Para que não exista confusão terminológica vamos considerar "as línguas" como manifestação da "linguagem", desta forma podemos usar no texto um termo ou outro.

${ }^{3}$ Claro que poderíamos destacar as ideias de filósofos historicistas como Hegel ou as ideias de Darwin como contribuindo para o reconhecimento da contingência do ser humano.
} 
mundo constituídas por um conjunto de frases que são coerentes entre si. Desta forma, é recomendável abandonar a ideia de considerar frases isoladamente. Algumas razões para abandonar tal ideia: (i) frases tomadas isoladamente não fornecem uma compreensão razoável do mundo, já que precisaríamos de outras frases para entendê-lo; (ii) no caso de considerarmos jogos de linguagem alternativos para descrever o mundo, precisamos de um conjunto de frases coerentes entre si que permitam inferir certas conclusões.

O que pretendemos destacar é que as sugestões descritivas disponíveis, que podemos dar do mundo e de nós mesmos, são apresentadas como conjunto coerente de frases, como vocabulários completos ou como jogos de linguagem. Diz Rorty (2007, p. 29): “O vocabulário da antiga política ateniense versus o de Jefferson, o vocabulário moral de São Paulo versus o de Freud, o jargão de Newton versus o de Aristóteles...”.

Vocabulários como o da moral de São Paulo, como o da política ateniense e como o da moral de Freud são compostos por um conjunto de frases que são coerentes entre si. Não podemos considerar as frases destes vocabulários isoladamente. A tese coerentista da linguagem em filosofia foi defendida por Donald Davidson (2001, p. 141), que diz: "nada conta como uma razão para uma crença a não ser outra crença". Aqui podemos substituir o termo "crença" por "frase" ou "sentença". Desta forma, devemos investigar o vocabulário em que as frases são formuladas, e não as frases isoladamente.

Compreender a linguagem dessa forma nos faz entender, por exemplo, que o vocabulário de Newton nos permite prever o mundo de forma mais adequada do que o de Aristóteles; isto não significa dizer em termos ontológicos que o mundo fale newtoniano. Isso é apenas "o reconhecimento de que o mundo não nos diz quais jogos linguísticos devem ser adotados ou praticados" (RORTY, 2007, p. 30). A mudança de um vocabulário, de um jogo de linguagem para outro, ocorre quando perdemos aos poucos o hábito de usar certas palavras e aos poucos adquirimos o hábito de usar outras. Esse é um aspecto essencial para entendermos a contingência da linguagem, pois aponta para o caráter mutável das descrições que fornecemos de nós mesmos e do mundo.

No campo social e político, por exemplo, o problema é: qual vocabulário devemos adotar para descrevermos as instituições e a nós mesmos? Como filósofos, ficamos tentados a pensar a escolha em termos de critério. Qual o critério que podemos adotar para a escolha de determinado vocabulário? Seguindo a linha de raciocínio de Richard Rorty, defenderíamos que tal decisão não se pauta em nenhum critério objetivo; que tal decisão não seja nem 
arbitrária nem expressão de algo profundo ou essencial nos seres humanos. Rorty (2007, p. 30) defende que "a moral não determina que os critérios objetivos de escolha vocabular devam ser substituídos por critérios subjetivos, ou que a razão deva ser substituída pelos sentimentos".

A ideia de procurar critérios é uma espécie de tentação mais geral de pensar o mundo e o "eu humano" como possuidores de uma natureza intrínseca, de uma essência metafísica. No final das contas, a ideia de critério parece ser a tentativa de privilegiar uma dentre as muitas linguagens com que habitualmente descrevemos o mundo e a nós mesmos. Davidson e Rorty nos convidam, neste caso, a considerar duas teses:

(i) A linguagem é contingente.

(ii) A identidade humana é construída e redescrita pelo uso de vocabulários.

Adotar (i) e (ii) implica defender a ideia de que podemos mudar aquilo que somos por meio do uso de novos vocabulários. ${ }^{4}$ Por isso Rorty (2005, p. 210) considera que "dizer que somos animais inteligentes não significa dizer algo filosófico e pessimista”. Isso significa dizer algo político e esperançoso, a saber, se podemos trabalhar juntos, podemos nos transformar em algo corajoso e inteligente o quanto for possível. Significa também deixar de lado questões como “o que é o ser humano?” e substituí-las por questões como “que tipo de mundo podemos preparar para os que virão?’.

\section{MCDOWEII E A IDEIA DE RACIONALIDADE}

“... razões só começam a existir num jogo de linguagem” (WITTGENSTEIN, 2008, §689).

Abordaremos nesta segunda seção a história que John McDowell conta acerca da entrada do indivíduo no que Sellars chama de espaço lógico das razões, ou seja, o espaço de dar e pedir razões sobre o que acreditamos e fazemos. Consideramos que McDowell fornece elementos que podem colaborar com a ideia rortyana de descrições da identidade do indivíduo pela

\footnotetext{
${ }^{4}$ Vale lembrar que "vocabulário" em nosso texto é sinônimo de "jogo de linguagem".
} 
adoção de novos vocabulários. Nesse caso, penso na ideia de McDowell de que seres humanos podem acessar razões que servem para justificar crenças e ações.

De acordo com McDowell, a entrada do indivíduo no espaço das razões começa com a formação do caráter ético do indivíduo. Aqui caráter ético pode ser tomado como a iniciação nas práticas de um jogo de linguagem. A entrada no jogo de linguagem é a ideia de que o indivíduo aprendeu as regras de dar e pedir razões para crenças e ações. Tal aprendizado é o que caracteriza a iniciação no espaço das razões; a ideia de racionalidade se torna uma espécie de segunda natureza (MCDOWELL, [1994], 2005, p. 121). Esse caráter de iniciação no espaço das razões não pode ficar restrito ao campo prático. Escreve McDowell (p. 122): "moldar o caráter ético é um caso particular [...] de um fenômeno mais geral: a iniciação nas capacidades conceituais, que inclui responsividade a outras exigências racionais, além das exigências éticas". Ao ser iniciado no espaço das razões, o sujeito adquire olhos abertos para razões em geral.

Ter olhos abertos para as razões se refere à capacidade de o sujeito acessar racionalmente o conteúdo de sua experiência em primeira pessoa, ou seja, dar o passo atrás e livremente escolher o que fazer ou acreditar (MCDOWELL, 2005, p. 130). O conteúdo a que temos acesso em nossas experiências, como razões para acreditar e agir, é conceitual. Portanto, entrar no espaço lógico das razões é entrar na prática de um jogo de linguagem, ou seja, é adquirir a capacidade de oferecer e de pedir razões para justificar crenças e ações.

McDowell e Rorty concordam sobre o caráter contingente e histórico da linguagem, portanto, concordam que a identidade não é algo sobrenatural ou especial fornecido ao ser humano. McDowell acredita que a iniciação em um jogo de linguagem é a realização de uma potencialidade com a qual nascemos. Não é o caso de supor que ela introduza um ingrediente não animal em nossa constituição. Diz McDowell (2005, p. 126): “os significados só ganham visibilidade porque a educação (Bildung) tem a capacidade de abrir nossos olhos para eles - a iniciação no jogo de linguagem é um elemento no processo normal de nossa chegada à maturidade do tipo de animais que somos. O significado não é um presente misterioso que nos vem de fora da natureza".

Ao ser iniciado no jogo de linguagem, o ser humano é introduzido, antes mesmo de entrar em cena, em algo que já incorpora conexões supostamente racionais entre conceitos, conexões que são supostamente constitutivas da configuração do espaço lógico dos conceitos. Nesse caso, somos iniciados nos espaços das razões, tal como se pega um bonde andando. A 
capacidade de dar e pedir razões para justificar crenças e ações é uma característica natural do ser humano, uma potencialidade. Já a identidade humana, ou seja, a forma como nos enxergamos culturalmente não é fixa. Se mudarmos a forma como falamos de nós mesmos, mudamos aquilo que somos. Portanto, mudar o vocabulário ou a forma como falamos de nós mesmos, implica a mudança de crenças e ações.

Brandom alega que nesse jogo de dar e pedir razões está implicado o comprometimento consequencial. Uma jogada não pode ser sem propósito, ela deve fazer alguma diferença, deve ter consequências para o que lhe é apropriado fazer, de acordo com as regras do jogo. Alegações expressam crenças. "Colocar uma alegação na lista de crenças, tem consequências para como se deve, racionalmente, agir, julgar e crer.” (BRANDOM, 2013, p. 211). Brandom aponta para o fato de que os indivíduos devam ser responsabilizados por crenças, julgamentos e ações que colocam em prática. Por exemplo, se temos à disposição um conjunto de frases ou alegações que promovem a tolerância e o diálogo, mas adotamos alegações que alimentam o ódio e o preconceito, devemos ser responsabilizados consenquencialmente por crenças e ações motivadas por tais alegações.

Existem motivos habitando nosso mundo mental que não podem ser acessados conscientemente. Freud (2006) nos alerta para essa questão quando defende a existência de motivos inconscientes ou ocultos para crenças e ações. Tais motivos não figuram em nossa vida consciente. Aqui Freud apresenta um problema à compreensão intelectualista de razão. De que forma podemos falar de comprometimento consequencial, como propõe Brandom, se existem motivos que não podem ser acessados conscientemente, mas podem influenciar crenças, julgamentos e ações? Nesse caso, parece que estamos diante de motivos irracionais. Davidson (2001, p. 179) chama tais motivos ocultos ou inconscientes de "causas mentais, que não são razões". Freud nos convida a reconhecer a existência de dois motivos para crenças, julgamentos e ações: (i) motivos ocultos ou inconscientes e (ii) motivos conscientes, que também podemos chamar de razões.

A moral da história é que certas crenças, discursos e ações não podem ser justificados racionalmente, como é o caso de discursos, crenças e ações envolvidas em questões culturais e políticas que podemos chamar de irracionais. Aqui podemos pensar em comportamentos violentos e preconceituosos (racismo, preconceito relativo à orientação sexual, deficiências e obesidade) motivados sem que o indivíduo tenha consciência. É o que mostra o Teste de Associação Implícita (IAT). O teste foi introduzido há duas décadas na universidade de 
Harvard como uma maneira de medir o preconceito implícito (TESTE DE ASSOCIAÇÃO IMPLÍCITA, 2018). ${ }^{5}$

Vejamos, por exemplo, o teste aplicado à questão étnica: aparecem diversas palavras e rostos. As palavras podem ser positivas como "maravilha", "amizade", "feliz" e "comemore" ou negativas como “dor", “desprezo", “sujo" e "desastre”. Em uma parte do processo, é preciso pressionar uma tecla toda vez que você perceber visualmente um rosto de uma pessoa negra ou uma palavra ruim e pressionar outra tecla quando aparecer um rosto de uma pessoa branca ou uma palavra boa. Em seguida, o jogo vira: uma tecla para rostos negros e palavras boas e outra para rostos brancos e palavras ruins. Você precisa pressionar a tecla apropriada o mais rápido possível. $\mathrm{O}$ computador mede a velocidade.

O resultado não surpreende. A maior parte dos indivíduos demonstra inclinação a favor dos rostos brancos. As pessoas submetidas ao teste conectam mais rapidamente rostos de pessoas negras a conceitos ruins do que rostos brancos. O que mais surpreende é que pessoas negras não são imunes a esse fenômeno. A grande questão é que crenças e visões como essas que alimentamos inconscientemente são mais aderentes e difíceis de erradicar, o que acarreta no enviesamento do nosso raciocínio.

Esses comportamentos não são manifestados na maioria das vezes de forma consciente? Comportamentos preconceituosos são manifestados de forma consciente. O que destacamos é que podemos reforçar discursos e comportamentos intolerantes e preconceituosos adotando determinado jogo de linguagem. Nesse caso, o que é possível fazer é sugerir descrições alternativas de nós mesmos que favoreçam a tolerância e o diálogo, capazes de operar tanto no nível consciente como no nível inconsciente.

\section{REDESCREVENDO REALAÇÕES SOCIAIS E POLÍTICAS}

Nesta seção defendemos o que acreditamos ser uma proposta para que as relações sociais, culturais e políticas (relações de poder) sejam mais justas. A sugestão é a de que devemos adotar vocabulários ou jogos de linguagem que incluam termos e discursos capazes de promoverem a tolerância e o diálogo e excluam discursos de ódio e preconceito. É essa atitude que vai permitir formar indivíduos capazes de construir uma sociedade mais tolerante.

\footnotetext{
${ }^{5}$ Toda a descrição do teste foi retirada dessa fonte.
} 
Isso é possível porque a identidade humana não é algo rígido, imutável. O uso de jogos de linguagem que excluam discursos de ódio e preconceito diminui as chances de afirmações como "os brancos são superiores aos negros", ou perguntas como "são os homens superiores às mulheres?". Eliminar tais perguntas, falar de forma nova sobre as relações entre os indivíduos implica a construção de sociedades mais inclusivas.

Nesse caso, a filosofia funcionaria como uma espécie de "política cultural". Rorty (2009, p. 19) diz que o termo política cultural "abrange, entre outras coisas, disputas sobre o uso corretos das palavras [...] e inclui também projetos para se livrar de tópicos inteiros de discurso". O papel da filosofia é realizar um exame, de maneira implícita ou explícita, entre "a disputa de um vocabulário arraigado, que se transformou num incômodo, e um novo vocabulário, parcialmente formado, que traz a vaga promessa de coisas grandiosas" (RORTY, 2007, p. 34).

O método da filosofia, no âmbito cultural e político, deve consistir em descrever uma porção de coisas de maneira nova, até criar um padrão de conduta linguística que leve a geração em ascensão a adotá-la. O objetivo é originar "formas apropriadas" de comportamento linguístico e não linguístico. A noção “formas apropriadas” pode ser entendida em termos de "sociedades mais inclusivas". Esse tipo de filosofia funciona de forma holística, nos convidando a dizer coisas como: "tente pensar nisso desta maneira", ou, mais especificamente, "tente ignorar as questões tradicionais visivelmente fúteis, substituindo-as pelas seguintes questões novas e possivelmente interessantes" (RORTY, 2007, p. 35).

A ideia é de que seria mais adequado às nossas instituições sociais um vocabulário de reflexões morais e políticas que levassem em consideração perguntas como: que tipo de mundo podemos preparar para os futuros habitantes? De que forma podemos evitar o sofrimento dos nossos semelhantes humanos? Se levarmos em consideração tal proposta seremos capazes de criar instituições mais justas. Isso possibilitaria maximizar a qualidade da educação, a liberdade de expressão, a tolerância, o acesso à informação e a maior participação dos indivíduos nas decisões políticas. Portanto, descrever a nós mesmos e às nossas instituições de uma nova maneira equivale a otimizar o equilíbrio entre deixar as pessoas viverem sua vida privada e impedir o sofrimento alheio.

Acreditamos que já existe em curso uma profunda mudança na forma como descrevemos a nós mesmos e às nossas instituições. Quando certos grupos sugerem a 
exclusão de termos e discursos que alimentam violência, preconceito e intolerância estão forçando uma mudança nos discursos do vocabulário vigente. Essa revisão possibilita o exercício de novas práticas políticas e culturais. Um dos termos que deveríamos adotar em nossos discursos para novas práticas políticas e culturais é "um de nós” (SELLARS, 1968, p. 222). O uso de termos como "um de nós" viabiliza discursos inclusivos, tolerantes e não xenófobos.

Vejamos casos em que o termo "um de nós" deveria ser aplicado, mas não é: David Rieff em reportagem realizada na Bósnia (resultante da dissolução da Iugoslávia) para o New Yorker em 1992 relata que para os sérvios, os mulçumanos não são humanos... são apenas prisioneiros mulçumanos, enfileirados e estendidos no chão, prontos para serem executados. Os assassinos e estupradores sérvios não se consideravam violadores dos direitos humanos, pois não estavam fazendo essas coisas a seres humanos, mas a mulçumanos (RORTY, 2005, p. 199).

Os sérvios pensam que estão distinguindo os verdadeiros humanos dos pseudohumanos. Acham que estão agindo em nome dos interesses da verdadeira humanidade, dessa forma purificando o mundo. Os sérvios acreditam que existem por aí formas humanoides dignas de respeito, e tais casos consistem em casos paradigmáticos de humanidade, enquanto outros, muito diferentes de nós no comportamento e nos costumes, são, na melhor das hipóteses, casos duvidosos de seres humanos.

Acontece o mesmo quando queremos excluir as mulheres do conceito de "ser humano". Nesse caso, usamos o termo "homem" como sinônimo de "ser humano". Esse uso reforça a satisfação dos homens de não terem nascido mulheres. Ser um não macho é o terceiro modo de ser um não humano. No caso de questões étnicas, podemos pensar em situações em que a "cor preta" é associada a aspectos negativos. Discursos que usam expressões como "a coisa ficou preta", quando existe um problema manifesto ou "isso é coisa de preto", quando algo não é feito de forma adequada, só servem para alimentar a ideia de que indivíduos brancos são superiores. Como diz Clifford Geertz (2008, p. 16): “As mais importunas afirmações de humanidade feitas pelos homens são lançadas com tons de orgulho de grupo".

A mudança em práticas discursivas ou vocabulários que alimentam ódio, intolerância e o preconceito passa pelo fato de assumirmos que podemos trabalhar juntos, de que podemos nos transformar em indivíduos corajosos e inteligentes. A pergunta "o que nos faz diferentes 
dos outros animais?" não pode simplesmente ser respondida por uma afirmação como "nós podemos conhecer e eles apenas sentir". Aqui é o caso de respondermos como Rorty (2005, p. 211) sugere: "podemos sentir uns pelos outros algo em uma extensão muito maior do que eles". Nesse caso, cabe alimentar o sentimento de que o outro é "um de nós". Só assim podemos aumentar o grau de tolerância de certos grupos sociais em relação a outros.

O progresso moral passa pela pergunta “o que podemos fazer de nós?”. Para Rorty (2005, p. 203), tal questão nos direciona para o reconhecimento da flexibilidade humana. Começamos a nos considerar como um animal flexível, versátil e automoldável. Esse reconhecimento nos permite concentrar as energias em (i) promover a educação dos sentimentos e (ii) promover descrições capazes de criar sociedades mais inclusivas e tolerantes. Isso é capaz de deixar pessoas diferentes familiarizadas umas com as outras, de modo que sintam menos tentadas a pensar que aquelas que são diferentes delas sejam apenas semi-humanas (p. 211).

\section{CONSIDERAÇÕES FINAIS}

Vimos que as relações de poder serão mais justas quando começarmos a nos redescrever linguisticamente de maneira nova, criando um padrão de conduta linguístico que, se adotado, será capaz de promover formas apropriadas de comportamento não linguístico. Sugerimos que devemos adotar vocabulários ou jogos de linguagem que incluam termos e discursos capazes de gestar tolerância, diálogo e excluam discursos de ódio e preconceito. $\mathrm{O}$ uso de tais jogos de linguagem que excluam discursos de ódio e preconceito diminui as chances de afirmações como "os brancos são superiores aos negros", ou perguntas como "são os homens superiores às mulheres?". Eliminar tais afirmações e perguntas, falar de forma nova sobre as relações entre os indivíduos implica a construção de sociedades mais inclusivas.

\section{REFERÊNCIAS}

ARENDT, Hannah. Poder e violência. Rio de Janeiro: Relume Dumará, 2001.

BRANDOM, Robert. Articulando razões: uma introdução ao inferencialismo. Tradução de Agemir Bavaresco. Porto Alegre: EDIPUCRS, 2013.

DAVIDSON, Donald. (1983). A Coherence Theory of Truth and Knowledge: Subjective, Intersubjective, Objective. Oxford: Oxford University Press. 2001, p. 137-153. 
FREUD, Sigmund. Edição Standard brasileira das obras psicológicas completas de Sigmund Freud v. IV: a interpretação dos sonhos vol. I. Rio de Janeiro: Imago, 2006.

GEERTZ, Clifford. A interpretação das culturas. Rio de Janeiro: LTC, 2008.

MCDOWELL, John. Mente e mundo. Tradução de João Vergílio Gallerani Cuter; ensaio introdutório Hilan Bensusan. Aparecida, SP: Ideias \& Letras, 2005.

RORTY, Richard. A filosofia e o espelho da natureza. 2. ed. Tradução de Antônio Trânsito. Rio de Janeiro: Relume Dumará, 1994.

RORTY, Richard. Contingência, ironia e solidariedade. Tradução de Vera Ribeiro. São Paulo: Martins Fontes, 2007.

RORTY, Richard. Filosofia como política cultural. Tradução de João Carlos Pijnappel. São Paulo: Martins Fontes, 2009.

RORTY, Richard. Verdade e progresso. Barueri, SP: Manoele, 2005.

SELLARS, W. Science and metaphysics: variations on kantian themes. New York: Humanities P., 1968.

TESTE DE ASSOCIAÇÃO IMPLICITA. Disponível em: <https://implicit.harvard.edu/implicit/brazil/> Acesso em: 22 jan. 2018.

WITTGENSTEIN, Ludwig. (1953). Philosophische Untersuchungen/Philosophical Investigations. Edição bilíngue. 3. ed. Tradução de G. E. M. Anscombe. Blackwell, 1997.

WITTGENSTEIN, Ludwig. Investigações Filosóficas. 2. ed. Tradução de José Carlos Bruni. São Paulo: Abril Cultural, 1979. (Os Pensadores).

WITTGENSTEIN, Ludwig. Observações sobre a filosofia da psicologia. Aparecida, SP: Ideias \& Letras, 2008. (Coleção subjetividade contemporânea). 